\title{
Vegetation fires and release of radioactivity into the air
}

\author{
F. P. Carvalho, J. M. Oliveira \& M. Malta \\ Nuclear and Technological Institute, \\ Department of Radiological Protection and Nuclear Safety, Portugal
}

\begin{abstract}
Naturally-occurring radionuclides, such as those of the uranium and thorium series, as well as artificial radionuclides, are accumulated in plants generally in low concentrations. Summer vegetation fires release these natural and man-made radionuclides into the atmosphere. Concentrations of uranium isotopes ${ }^{238} \mathrm{U}$, ${ }^{235} \mathrm{U},{ }^{234} \mathrm{U},{ }^{232} \mathrm{Th},{ }^{230} \mathrm{Th},{ }^{226} \mathrm{Ra},{ }^{210} \mathrm{~Pb}$ and ${ }^{210} \mathrm{Po}$ were measured in smoke from wild vegetation fires. It is shown that radionuclide concentrations in smoke particles are enhanced about 100 times in comparison with the vegetation of the area and with reference aerosols. Smoke particles were particularly enriched in ${ }^{210} \mathrm{Po}$, and displayed ${ }^{210} \mathrm{Po} /{ }^{210} \mathrm{~Pb}$ activity concentration ratios always above unity and up to 12 , while in common aerosols ${ }^{210} \mathrm{Po} /{ }^{210} \mathrm{~Pb}$ is always $<1$. Inhaled smoke particles from vegetation and forest fires may contribute to enhanced radiation doses in the human lung.

Keywords: naturally-occurring radionuclides, polonium, radioactivity in plants, vegetation fires.
\end{abstract}

\section{Introduction}

Every year, especially in the inter-tropical and temperate regions a high number of wild forest and vegetation fires causes loss of property and natural resources. The wild vegetation and forest fires release into the atmosphere large quantities of volatilized substances and particulate matter, aggravated by those from man made fires either for combustible control, agriculture fires, and plant biomass burning for heat production, all of them with an impact on atmospheric chemistry and a potential impact on climate change [1,2]. Recent studies have increasingly focused on the impact of fire emissions on human health and 
especially on the diseases of the respiratory tract in firemen and on the population at large [3].

More than 200 substances have been identified in the composition of smoke from forest and vegetation fires [3, 4]. Amongst them were investigated as health damaging substances the carbon monoxide, respirable particles, formaldehyde, acrolein, benzene, and toluene. NOx compounds and metals are also released into the air by the bush fires, although not much information on these has been obtained as yet [3]. The burn of wood and other plant materials (e.g., tree bark) for heat production both at industrial scale as well as in fireplaces at home have been investigated as sources of exposure to toxic compounds in the indoor air [5].

Radionuclides are a group of elements that were addressed rarely in the studies related to fire smoke exposure, with the exception of concerns with radioactive caesium, mainly ${ }^{137} \mathrm{Cs}$, from the Chernobyl accident and deposited in soils in Ukraine and Belorussia [6]. Forest fires occurring in Spring and Summer in those regions of the Eastern Europe, have re suspended ${ }^{137} \mathrm{Cs}$ formerly deposited on soils and allowed for atmospheric transportation and the detection of enhanced ${ }^{137} \mathrm{Cs}$ activity peaks in the air at neighbour countries [6, 7].

Besides artificially produced radionuclides, such as ${ }^{137} \mathrm{Cs}$, the bush vegetation and forest trees (tree trunks and leaves) contain naturally-occurring radionuclides that they absorb from the soil and from the surface air. Although these concentrations are generally low, the burning of plant biomass has tremendously increased in recent years in Europe. In Portugal alone, during the last decade wild fires burned in average 150000 ha per year, which represented 50\% more than the annual average area burned in the previous decade. This has been the common trend around the Mediterranean basin, creating an extended exposure of large populations to smoke from vegetation and forest fires in the region.

This paper reports on naturally occurring radionuclides present in smoke particles from vegetation fires in Portugal and makes a comparison with the cigarette smoke as a preliminary step to the health risk assessment of exposure to smoke from vegetation fires.

\section{Materials and methods}

\subsection{Sampling methods}

Wild vegetation fires were sampled in September 2010 in collaboration with firemen in the rural areas of the North of Portugal (Montalegre, Trás os Montes). The surveyed fires burned wild bush areas with reduced forest (soil cover by trees less than 10\%), but with dense Mediterranean "maquis" vegetation type. Several fires were monitored and surface air samples collected at around $1 \mathrm{~m}$ above the ground, either near the fire front (flames) or in areas several hundred meters away from the fire front in the smoke plume.

The aerosol samples from the fire front, naturally comprising mainly smoke particles and fly ash, were collected using a portable battery powered vacuum pump (F\&J Specialty, USA) with digital control of flow rate, total volume and 
sampling time. Aerosol samples were collected on Whatman microfiber glass filters (average $0.7 \mu \mathrm{m}$ pore size) of $5 \mathrm{~cm}$ diameter.

Aerosol samples away from the fire front were collected with high volume samplers from F\&J Specialty and Andersen. Typically, each sample corresponded to about $100 \mathrm{~m}^{3}$ of air volume filtered. Air samplers were used as fixed monitoring stations and powered with a portable electric generator. Filters used were respectively circular filters with $9 \mathrm{~cm}$ diameter and rectangular filters of $20 \times 25 \mathrm{~cm}$, microfiber glass (Whatman). All filters were pre weighted and weighted again after the sampling and oven drying at $60^{\circ} \mathrm{C}$ in order to determine the amount of particulate material collected. This enabled to calculate the radionuclide concentrations per weight of aerosol particulates and per unit of air volume filtered.

In the same region monitored for vegetation fires, vegetation samples, including thorny bush, leafy green vegetation, and leaf litter were collected. These samples were dried, homogenized and sample aliquots analyzed for radionuclide concentrations.

\subsection{Analytical methods}

Radionuclide analysis targeted the alpha emitting radionuclides of the uranium and thorium series, namely ${ }^{238} \mathrm{U},{ }^{235} \mathrm{U},{ }^{234} \mathrm{U},{ }^{232} \mathrm{Th},{ }^{230} \mathrm{Th},{ }^{226} \mathrm{Ra},{ }^{210} \mathrm{Po}$ and ${ }^{210} \mathrm{~Pb}$. in the beginning of the analytical procedure, to each sample were added isotopic tracers $\left({ }^{232} \mathrm{U},{ }^{229} \mathrm{Th},{ }^{224} \mathrm{Ra},{ }^{209} \mathrm{Po}\right.$, and stable $\left.\mathrm{Pb}^{2+}\right)$ to allow the quantification of the radiochemical yield. After separation and purification, each radioelement was electroplated onto a stainless steel disc (replaced by an Ag disc for polonium) and the radioactivity emitted from the disc measured with ion implanted silicon detectors and an alpha spectrometer OctetePlus (Ortec EG\&G). The methods used were previously described and validated [8,9]. The quality assurance of the results was regularly controlled with the analysis of certified reference materials and participation in international intercomparison exercises organized by the International atomic Energy Agency with good results [9].

\section{Results}

Figure 1 shows the results for two radionuclides, ${ }^{210} \mathrm{~Pb}$ and ${ }^{210} \mathrm{Po}$ in aerosol particles collected on small diameter microfiber glass filters near the fire front. One aerosol reference sample was collected in the absence of fires and the particle load recorded, mainly made of re-suspended soil dust, was the lowest, $0.21 \mathrm{mg} / \mathrm{m}^{3}$. The radionuclide concentrations and the ${ }^{210} \mathrm{Po} /{ }^{210} \mathrm{~Pb}$ activity concentration ratio in this reference sample, 0.30 , was in the range of ${ }^{210} \mathrm{Po} /{ }^{210} \mathrm{~Pb}$ ratios in surface air (average ratio 0.19, range 0.03-0.78), previously reported for the Lisbon area [10]. The other aerosol samples were collected very close to the vegetation fires. The particulate concentration in the air varied from sample to sample, as smoke does in the fire zones. Concentrations of both radionuclides in the smoke samples increased in average by a factor of about 100 compared to the reference sample. Moreover, in all these smoke samples the ${ }^{210} \mathrm{Po}$ concentrations 
were systematically higher than those of ${ }^{210} \mathrm{~Pb}$, with ${ }^{210} \mathrm{Po} /{ }^{210} \mathrm{~Pb}$ ratios up to 12 . Radionuclides were clearly associated with the smoke and fly ash particles produced by the vegetation fire and the activity concentration ratios were the reverse in comparison with the reference aerosol sample $(<1)$ due to much higher ${ }^{210} \mathrm{Po}$ concentrations in the smoke compared to those of ${ }^{210} \mathrm{~Pb}$.

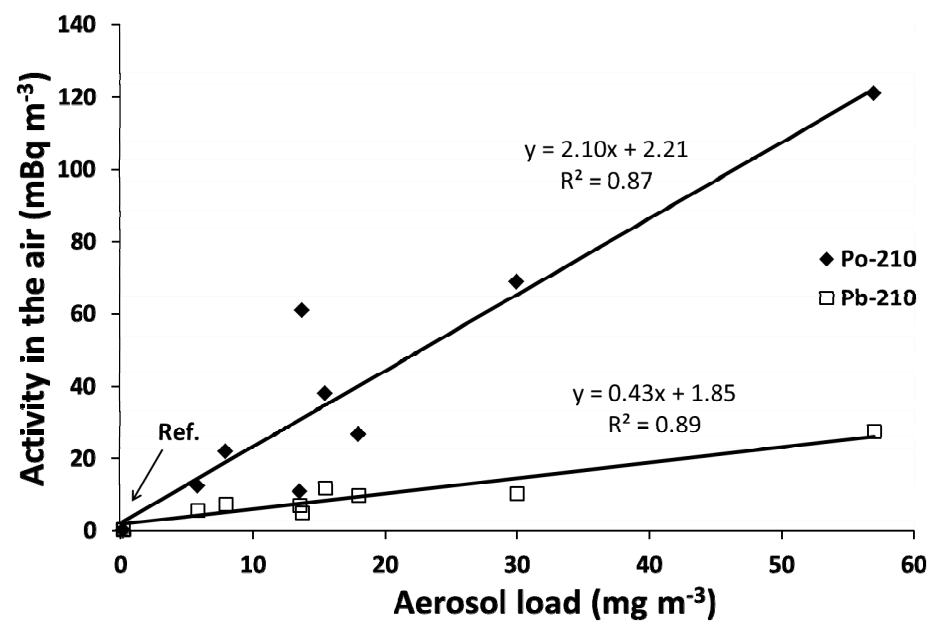

Figure 1: $\quad$ Polonium $\left({ }^{210} \mathrm{Po}\right)$ and radioactive lead $\left({ }^{210} \mathrm{~Pb}\right)$ concentrations in the surface air and their increase with the load of smoke particles from vegetation fires, near the fire. The first sampling point (included in the regression fits) is from a reference aerosol. Correlations are statistically significant at $\mathrm{p}<0.001$.

Filters with large volume samples were analyzed for the entire set of alpha emitting radionuclides targeted in this study. Results are partly displayed in Figure 2. Concentrations of all radionuclides per unit of air volume $\left(\mu \mathrm{Bq} / \mathrm{m}^{3}\right)$ increased in the smoke of vegetation fires in comparison to the reference aerosol sample. Specific activity of radionuclides $(\mathrm{Bq} / \mathrm{kg}$ aerosol particulates) increased also in the smoke particles in comparison with the reference aerosol. This increase in aerosol specific activities was in average 10 times higher for uranium isotopes, ${ }^{230} \mathrm{Th}$, and ${ }^{226} \mathrm{Ra} .{ }^{232} \mathrm{Th}$, the parent radionuclide of the thorium series, which is a good indicator of soil dust re-suspension, was present in the smoke in specific activities either similar or slightly higher than in the reference aerosol. A slight increase may be due to dust re-suspension in the fire zone caused by the hot air and atmospheric turbulence. Nevertheless, ${ }^{232} \mathrm{Th}$ in smoke particles was always lower than ${ }^{238} \mathrm{U},{ }^{230} \mathrm{Th}$, and ${ }^{226} \mathrm{Ra}$ released from the vegetation by the combustion. Specific activities in smoke particles were higher for ${ }^{210} \mathrm{Po}$ and ${ }^{226} \mathrm{Ra}$ than for other radionuclides, such as uranium and thorium isotopes. This is likely related to the lower volatilization temperature of polonium and radium in comparison with the other radioelements. 


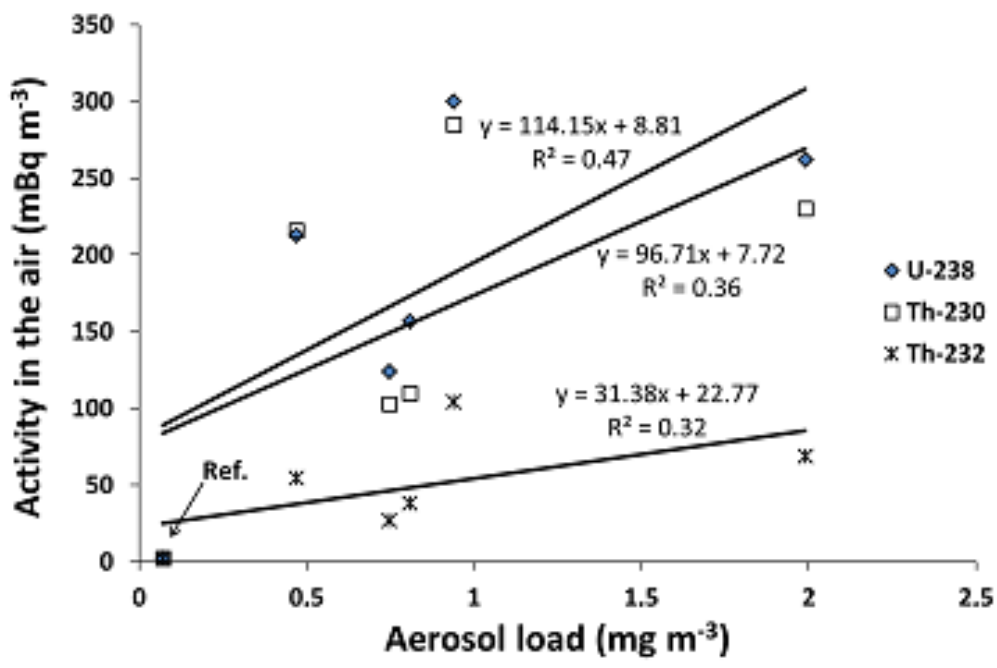

Figure 2: Increase of activity concentrations of radionuclides ${ }^{238} \mathrm{U},{ }^{230} \mathrm{Th}$, ${ }^{232} \mathrm{Th}$, in surface air with the increase of the load smoke particles from vegetation fires in the region. The first sampling point (included in the regression fits) is from a reference aerosol. Correlation fits are statistically significant at $\mathrm{p}<0.20$ only.

Data for several types of vegetation and leaf litter from the region of surveyed fires are shown in Table 1. Concentrations of radionuclides were all low and, on a mass basis, much lower in vegetation than in smoke particles released by the vegetation fires.

Table 1: $\quad$ Radionuclide concentrations ( $\mathrm{Bq} \mathrm{kg}^{-1}$ dry weight) in the vegetation and leaf litter of the region investigated. Uncertainties of concentrations are about $5 \%$.

\begin{tabular}{lcccccc}
\hline & ${ }^{238} \mathbf{U}$ & ${ }^{235} \mathbf{U}$ & ${ }^{234} \mathbf{U}$ & ${ }^{\mathbf{2 3 0}} \mathbf{T h}$ & ${ }^{226} \mathbf{R a}$ & ${ }^{{ }^{232}} \mathbf{T h}$ \\
\hline Thorny bush \#1 & 0.00142 & $5.90 \mathrm{E}-05$ & 0.00144 & 0.0016 & 0.066 & 0.00089 \\
Leaf litter \#2 & 6.1 & 0.27 & 6.0 & 7.2 & 56.1 & 2.9 \\
Grasses \#4 & 0.94 & 0.044 & 0.94 & 0.90 & 5.3 & 0.40 \\
Ferns \#5 & 0.25 & 0.016 & 0.22 & 0.21 & 13.4 & 0.097 \\
Leaf litter \#6 & 0.88 & 0.032 & 0.89 & 0.86 & 7.3 & 0.42 \\
\hline
\end{tabular}




\section{Discussion and conclusions}

The vegetation fires release the naturally-occurring radionuclides contained in the vegetation and, although part of them may remain on the ground associated with the ashes, important radionuclide amounts become associated with smoke particles and fly ash released into the atmosphere. From a radiation protection point of view, the naturally occurring radionuclides more relevant to the radiation dose are the uranium series decay products, particularly the alpha emitting radionuclides such as ${ }^{210} \mathrm{Po}$ and ${ }^{226} \mathrm{Ra}$. On a mass basis $(\mathrm{Bq} / \mathrm{kg})$, the smoke from vegetation fires displayed radionuclide concentrations about 100 times higher than a reference aerosol collected in the absence of smoke. The smoke particles were clearly enriched in ${ }^{210} \mathrm{Po}$ and ${ }^{226} \mathrm{Ra}$ in comparison with the reference aerosol and in comparison with non burned bush and leaf litter from the same region.

Inhalation of smoke particles may be harmful by a number of physicalchemical mechanisms as shown by several studies. Evidence was provided that asthma and other respiratory diseases are positively correlated with the exposure to high suspended particulate loads in the air, including smoke from forest fires [11]. The results presented herein indicate that inhalation of smoke from vegetation fires increases the lung exposure to radioactivity, and especially to alpha emitting radionuclides such as the ${ }^{210} \mathrm{Po}$.

The ${ }^{210}$ Po concentrations measured in smoke sampled near the vegetation fire front are representative of the smoke inhalation by firemen during fire fighting operations. For ${ }^{210} \mathrm{Po}$ concentrations of $120 \mathrm{mBq} / \mathrm{m}^{3}$ and assuming a one day exposure to the fire smoke, the inhalation of $20 \mathrm{~m}^{3}$ of air will correspond to the ${ }^{210} \mathrm{Po}$ inhalation rate of $2.4 \mathrm{~Bq} /$ day. This value may be compared with the average ${ }^{210} \mathrm{Po}$ inhalation in Lisbon area, of about $6.62 \times 10-4 \mathrm{~Bq} / \mathrm{d}$, and with the ${ }^{210} \mathrm{Po}$ inhalation of a one-pack-a-day cigarette smoker, $30 \mathrm{mBq} / \mathrm{d}[10]$. The inhalation exposure to the smoke from vegetation fire over a one day may represent for a fireman a ${ }^{210}$ Po inhalation about 80 times higher than a cigarette smoker and about 4000 times higher than inhalation of atmospheric background ${ }^{210}$ Po by a member of the public.

These findings clearly show that vegetation fires increase the radioactivity levels in the atmosphere. Smoke particles from vegetation fires may also increase the lung exposure to enhanced levels of alpha emitting radionuclides and, thus, the respiratory tract protection of firemen is needed because also of the presence of carcinogenic radionuclides. The effect of radioactivity in smoke from the vegetation fires on the population at large shall be assessed namely with the support of aerosol particles characterization and measurement of the inhalable fraction.

\section{Acknowledgements}

This work was funded by "Fundação para a Ciência e Tecnologia", Portugal, Research Contract Nr. PTDC/AMB/65706/2006. 


\section{References}

[1] Jayasekher, T., Aerosols near by a coal fired thermal power plant: Chemical composition and toxic evaluation. Chemosphere, 75, 1525 - 1530, 2009.

[2] Lazaridis, M., Latos, M., Aleksandropoulou, V., Hov, Ø, Papayannis, A., Tørseth, K., Contribution of forest fire emissions to atmospheric pollution in Greece, Air Quality, Atmosphere and Health, 1:143 - 158, 2008.

[3] Johnston, F.H., Rosalind, J. W., Pilotto, L., Bailie, R.S., Parry, D. L., Halpin, S., Vegetation fires, particulate air pollution and asthma: A panel study in the Australian monsoon tropics. International Journal of Environmental Health Research, 16(6): 391 - 404, 2006.

[4] Vos, A.J.M.D., Reisen, F., Cook, A., Devine, B., Weinstein, P., Respiratory Irritants in Australian Bushfire Smoke: Air Toxics Sampling in a Smoke Chamber and During Prescribed Burns, Archives of Environmental Contamination and Toxicology, 56: 380 - 388, 2009.

[5] Gonçalves, C., Alves, C., Evtyugina, M., Mirante, F., Pio, C., Caseiro, A., Schmidl, C., Bauer, H., Carvalho, F., Characterisation of PM10 emissions from woodstove combustion of common woods grown in Portugal. Atmospheric Environment, 44 (35), 4474 - 4480, 2010.

[6] Paatero, J., Vesterbacka, K., Makkonen, U., Kyllonen, K., Hellen, H., Hatakka, J., Anttila, P., Resuspension of radionuclides into the atmosphere due to forest fires. Journal of Radioanalytical and Nuclear Chemistry, 282, (2): $473-476,2009$.

[7] Jargin, S., Forest fires in the former Soviet Union: no reasons for radiophobia. Journal of Environmental Radioactivity, 102, 218 - 219, 2011.

[8] [8] Oliveira, J.M., Carvalho, F.P. A Sequential Extraction Procedure for Determination of Uranium, Thorium, Radium, Lead and Polonium Radionuclides by Alpha Spectrometry in Environmental Samples. (Proceedings of the 15th Radiochemical Conference). Czechoslovak Journal of Physics 56 (Suppl. D): 545-555, 2006.

[9] Carvalho F.P., Oliveira, J.M. Alpha emitters from uranium mining in the environment. Journal of Radioanalytical and Nuclear Chemistry 274: 167174, 2007.

[10] Carvalho, F.P. Origins and concentrations of ${ }^{222} \mathrm{Rn},{ }^{210} \mathrm{~Pb},{ }^{210} \mathrm{Bi}$ and ${ }^{210} \mathrm{Po}$ in the surface air at Lisbon, Portugal, at the Atlantic edge of the European continental landmass. Atmospheric Environment 29 (15): 1809-1819, 1995.

[11] Carvalho, F.P. ${ }^{210} \mathrm{Po}$ and ${ }^{210} \mathrm{~Pb}$ intake by the Portuguese population: the contribution of seafood in the dietary intake of ${ }^{210} \mathrm{Po}$ and ${ }^{210} \mathrm{~Pb}$. Health Physics 69(4): 469-480, 1995. 